\title{
Fazer Marielle Franco presente: história de vida, interseccionalidade e sociologia
}

\section{Camila Santos Pereira 1 (i)}

Programa de Pós-Graduação em Educação da Universidade do Estado do Rio de Janeiro (ProPEd/UERJ).

\section{Relatos de Experiência | Experience reports | Informes de experiencia} DOI do artigo: 10.22481/odeere.v6i01.8086

\section{RESUMO}

A partir dos questionamentos de uma turma de Sociologia do Ensino Médio, bastante comovida com o assassinato da vereadora Marielle Franco, que causou comoção nacional, foi organizada uma atividade para apresentar sua trajetória pessoal e política. No intuito de fundamentar a aula na perspectiva interseccional, o recurso didático principal representou a silhueta do rosto de Marielle, em forma de desenho, composto de cinco partes indissociáveis. Cada fragmento trazia uma categoria sociológica: classe, raça, gênero, sexualidade e protagonismo, que, debatidas com a turma, previamente à colagem de cada peça, promoveram reflexões sobre o significado dos conceitos e de como se entrelaçam à história de vida de Marielle. O trabalho abordou conceitos clássicos das Ciências Sociais, como o de fato social de Émile Durkheim, por meio de um olhar inventivo e partindo de uma problematização suscitada pela turma.

Palavras-chave: interseccionalidade; didática; sociologia; educação; história de vida.

\section{Making Marielle Franco present: life history, intersectionality and sociology teaching}

\section{ABSTRACT}

Based on the questions raised by a high school sociology class, very moved by the murder of city councilwoman Marielle Franco, which caused national commotion, an activity was organized to present her personal and political trajectory. In order to base the class on the intersectional perspective, the main didactic resource represented the silhovette of Marielle's face, in the form of a drawing, composed of five inseparable parts. Each fragment had a sociological category: class, race, gender, sexuality and protagonism, which, discussed with the class, prior to the collage of each piece, promoted reflections on the meaning of the concepts and how they intertwine with Marielle's life story. The work approached classic concepts of Social Sciences, such as Émile Durkheim's social fact, through an inventive look and starting from a problematization raised by the class.

Keywords: intersectionality; didactic; sociology; education; life's history.

Submetido em: 21 de fev. de 2021 | Aceito em: 16 de abr. de 2021

\section{Introdução}

Este artigo visa relatar as experiências vividas e os métodos utilizados na atividade: "Marielle Franco e o que a Sociologia tem a ver com isso?". Aula desenvolveu-se como parte da disciplina de Estágio de Docência em Ciências Sociais I, do curso de graduação em Ciências Sociais - Licenciatura. Tal atividade foi desenvolvida no Colégio de Aplicação da Universidade, em uma turma do

\footnotetext{
1 Mestranda pelo Programa de Pós-Graduação em Educação da Universidade do Estado do Rio de Janeiro (ProPEd/UERJ). Especialista em Orientação Educacional (UNIASSELVI). Licenciada em Ciências Sociais (UFRGS). Integrante do Geni - estudos de gênero e sexualidade e do GEETRANS Grupo de Estudos em Educação e Transgressão. E-mail: fycamila@gmail.com
} 
ensino médio, no primeiro semestre de 2018. Logo após o assassinato de Marielle Franco, vereadora do Rio de Janeiro, aconteceram marchas em todo Brasil, e em diversos países ao redor do mundo, reivindicando justiça. Momento de grande repercussão também expresso dentro dos muros da escola. Na primeira semana depois do acontecido, parte considerável da turma chamou a atenção para esse fato. A professora titular, então, sugeriu que esse debate fizesse parte das minhas aulas do estágio que se iniciariam nas semanas seguintes. Como a turma estava discutindo temas introdutórios à Sociologia, a ideia desenvolvida articulou a trajetória política, acadêmica e pessoal de Marielle com os conceitos estruturantes da Sociologia de Émile Durkheim, principalmente sobre fato social. Para a grande maioria da comunidade acadêmica, na base do ensino de Sociologia estão os autores compreendidos como os clássicos, Émile Durkheim, Karl Marx e Max Weber. Por ser o primeiro contato da turma com a Sociologia, evidenciou-se a construção da disciplina como ciência e aplicação no cotidiano. Com a silhueta de Marielle Franco dividida em categorias sociológicas como: classe, raça, gênero, sexualidade e protagonismo, estabeleceu-se um diálogo com a turma a respeito das implicações desses conceitos na sociedade brasileira, enquanto, aos poucos, sua imagem era formada no quadro.

Exercício que exigiu muito mais do que a pesquisa histórico-cultural desses termos. Como professora negra e parte da comunidade LGBTQI+, falar sobre o acontecido resultou em um grande movimento pessoal, que demandou muitas reflexões sobre mente, corpo, sentimentos e o papel docente. Compreendo que a execução de Marielle Franco representou uma tentativa de calar seus ideais democráticos, seu combate às desigualdades raciais e sociais, de gênero, à violência policial e à discriminação de pessoas LGBTQI+. Seu assassinato repercurtiu como um ataque a milhares de existências. Absurdamente, dois anos e meio depois do acontecido, ainda reivindicamos justiça e desconhecemos o mandante do crime que ceifou as vidas de Marielle e Anderson Gomes, motorista da vereadora.

Por compreender a importância de dialogar a partir dos questionamentos surgidos em sala de aula, a relevância do tema e o papel da Sociologia em discutir e problematizar acontecimentos atuais, a aula de dois períodos de cinquenta minutos ganhou estrutura. Sendo assim, os escritos de Émile Durkheim e Lélia 
Pereira, C. S., Fazer Marielle Franco presente: história de vida, interseccionalidade e sociologia. ODEERE, v. 6, n. 01, jan./jun., p. 386-398, 2021. https://doi.org/10.22481/odeere.v6i01.8086

Gonzalez contribuíram para a construção do planejamento.

\section{Um pouco sobre a história de Marielle Franco}

A proposta de utilizar a história de vida como parte de uma metodologia para compreensão de fenômenos sociais está cercada por defesas e críticas. Para o sociólogo Pierre Bourdieu2, seria "conformar-se com uma ilusão retórica, uma representação comum da existência". No entanto, a aposta nesse método visa evidenciar, mesmo que de forma breve e inicial, um encontro entre teoria e cotidiano, aproximando discussões densas das mais distintas vivências, sem perder o cuidado e a atenção com os estudos científicos.

Marielle, mulher que cresceu na favela da Maré, assim como milhões de pessoas em nosso país, teve uma infância humilde e repleta de vivências próprias de territórios negligenciados pelo Estado. Como perder uma amiga em um confronto de balas perdidas. No entanto, essas experiências a transformaram em uma potência articulada em denunciar as violações e opressões que acontecem nesses territórios. Como acadêmica, temos sua dissertação intitulada "UPP - a redução da favela a três letras: uma análise da política de segurança pública do estado do Rio de Janeiro", produção que escancara o racismo institucionalizado e o controle dos corpos produzido pelas censuras, violências e leis. A partir de 2016, assume outro papel, o de vereadora da cidade do Rio de Janeiro. Assim, articula suas experiências pessoais e conhecimentos construídos na Universidade para defender os direitos das populações mais vulneráveis e denunciar abusos.

Marielle Franco, 38 anos, mulher negra, cria da favela da Maré, filha de Marinete e Antonio Francisco da Silva Neto, mãe de Luyara, namorada e companheira de vida de Monica Benício, estudante de cursinho popular, prounista, socióloga, mestra, professora, filiada ao Partido Socialismo e Liberdade (PSOL), com 46.502 votos tornou-se a quinta vereadora mais votada no Rio de Janeiro em 2016, ativista pelos direitos humanos, defensora das causas LGBTT+. Ativista acadêmica comprometida com a produção de uma escrita contrahegemônica e verdadeiramente preocupada com a efetividade das teorias que estudava. ${ }^{3}$

\footnotetext{
2 BOURDIEU, Pierre. A ilusão biográfica. In: Razões práticas: sobre a teoria da ação. 5. ed. São Paulo: Papirus Editora, 2005, p.74-82.

3 ESCOBAR, Geanine. Marielle, presente! Hoje e sempre. Dezanove, 2018. Disponível em: https://dezanove.pt/marielle-presente-hoje-e-sempre-1168931 Acessado em: 21/02/2021.
} 
Pereira, C. S., Fazer Marielle Franco presente: história de vida, interseccionalidade e sociologia. ODEERE, v. 6, n. 01, jan./jun., p. 386-398, 2021. https://doi.org/10.22481/odeere.v6i01.8086

Mulher negra, periférica, bissexual, mestre em administração, vereadora, protagonista de sua fala e relatora de diversas injustiças, desestabilizou os poderosos.

A aula constituiu-se como uma forma de resistência. Atualmente, o nome de Marielle está em centenas de camisetas e acessórios, no entanto, não podemos silenciar suas pautas. Para além de sua imagem, que hoje integra ondas significativas de compartilhamentos nos mais diferentes veículos, ela falava das desigualdades e exigia mudanças. Por esses motivos, fazer Marielle presente significa reivindicar, também nos espaços escolares e acadêmicos, articulações em prol de transformações necessárias. Urge falar das injustiças, sem ocultar o racismo, a LGBTQIfobia, o genocídio da população negra, o contínuo sequestro das terras indígenas e o crescimento do feminicídio no Brasil.

\section{Sociologia, compromisso social e os fatos sociais}

O papel da Sociologia no ensino médio enfatiza as práticas de desnaturalizar e proporcionar o estranhamento dos fenômenos sociais. Como uma disciplina comprometida com a análise crítica da sociedade, as desigualdades também são um objeto de estudo. Desde suas origens, as ciências sociais são filhas da democracia, consequentemente, são alvos de regimes conservadores e erradicadas pelos regimes ditatoriais ${ }^{4}$. Atualmente, observamos o atual presidente da República, Jair Bolsonaro, desmerecer e propor cortes nos investimentos nas faculdades de ciências humanas, principalmente na sociologia e na filosofia, por compreender que não existe um retorno imediato para a classe trabalhadora ${ }^{5}$. Em decisões como essa, analisamos "imprescindível transmitir, o mais racionalmente possível e para o maior número de pessoas, os meios de decifrar e de contestar os discursos de ilusão sobre o mundo social"6.

Trabalhar com o conceito de fato social de Émile Durkheim e relacionar com

\footnotetext{
${ }^{4}$ LAHIRE, B. "Viver e interpretar o mundo social: para que serve o ensino de Sociologia?" In: GONÇALVES, D. N. (Org.). Sociologia e juventude no ensino médio: formação, PIBID e outras experiências. Campinas: Pontes Editores, 2014.

${ }^{5}$ MAIA, Dhiego. Bolsonaro propõe reduzir verba para cursos de sociologia e filosofia no país. Folha de S.Paulo. Disponível em https://wwwl.folha.uol.com.br/educacao/2019/04/bolsonaro-propoereduzir-verba-para-cursos-de-sociologia-e-filosofia-no-pais.shtml Acessado em: 21/02/2021.

6 LAHIRE, B. 2014, p.50.
} 
os marcadores sociais da diferença foram alguns dos objetivos da aula. Assim, dialogamos com uma das ferramentas iniciais que a Sociologia utiliza para produzir uma análise científica da sociedade. Para Durkheim, fatos sociais devem ser tratados como coisas. Para o sociólogo7, coisa significaria o seguinte:

A coisa se opõe à ideia assim como o que se conhece a partir de fora se opõe ao que se conhece a partir de dentro. É coisa todo objeto do conhecimento que não é naturalmente penetrável à inteligência, tudo aquilo de que não podemos fazer uma noção adequada por um simples procedimento de análise mental, tudo o que o espírito não pode chegar a compreender a menos que saia de si mesmo, por meio de observações e experimentações, passando progressivamente dos caracteres mais exteriores e mais imediatamente acessíveis aos menos visíveis e aos mais profundos.

A partir dessa ideia de profundidade, de verificação e embasamento científico que as questões referentes às desigualdades sociais brasileiras e às identidades foram tratadas. O fato social serviu para introduzir os conceitos apresentados. Mesmo tratando de identidades, as conversas com a turma serviram para encaminhar aquelas discussões para identificar onde estaria presente o fato social naquelas relações. Posteriormente, preparou-se uma aula específica para abordar o conceito de fato social.

\section{Classe Social}

Após uma breve exposição dos objetivos da Sociologia e fato social, a colagem dos conceitos no quadro começa. Apresento para turma o tema da aula e explico que falaremos sobre a biografia de Marielle Franco. Colo no quadro a primeira parte do desenho: classe.

Figura 1 - Fragmento: classe

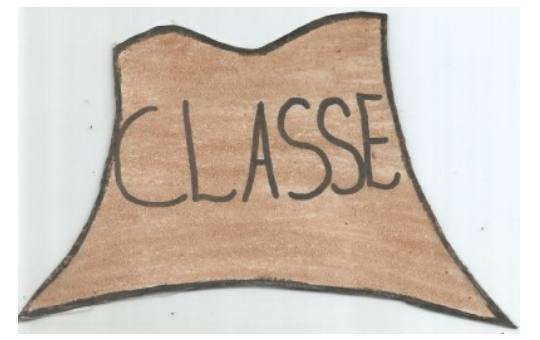

Fonte: elaborada pela autora.

Logo, discutimos sobre a origem de Marielle na favela da Maré e das desigualdades presentes nas periferias no Brasil. Após a introdução, pergunto: Qual

\footnotetext{
7 DURKHEIM, Émile. As regras do método sociológico. -3ª.ed.- São Paulo: Martins Fontes, 2007, p.17.
} 
a influência que a classe social de uma pessoa pode ter sobre sua trajetória pessoal? Depois desse questionamento, introduzo, rapidamente, uma das leituras clássicas de Karl Marx sobre o meio social e o capitalismo, a divisão entre burguesia e proletariado. Também evidencio que classe pode ter diversas características, pois ela pode ser fonte de todas as heranças simbólicas, valorativas, morais e existenciais que se passam de pais a filhos por laços de afeto, não apenas no conceito meramente econômico ${ }^{8}$. Nesse momento, alguns estudantes compartilham quais hábitos seriam característicos de sua classe social.

\section{Relações raciais}

As discussões acerca do conceito de raça possuem um longo histórico de divergências e debates nas ciências sociais. O planejamento da aula tratou $O$ conceito de raça como

[...] uma categoria discursiva e não uma categoria biológica. Isto é, ela é a categoria organizadora daquelas formas de falar, daqueles sistemas de representação e práticas sociais (discursos) que utilizam um conjunto frouxo, freqüentemente ponto específico, de diferenças em termos de características físicas - cor da pele, textura do cabelo, características físicas e corporais etc. - como marcas simbólicas, a fim de diferenciar socialmente um grupo de outro?.

Depois dessa distinção sobre como podemos trabalhar com o conceito de raça como construção social devido às desigualdades que essa separação reproduz, fiz três questionamentos e pedi que a turma levantasse a mão para respondê-los. O primeiro: quem acredita que existe racismo no Brasil? Toda a turma levantou a mão. O seguinte: quem na turma é racista? Ninguém levantou a mão e as expressões de dúvida ficaram estampadas em seus rostos. Após alguns segundos de silêncio, uma das alunas relata que o racismo está impregnado na nossa cultura, nas piadas que ela própria conta e não percebe que está reproduzindo o racismo. Lélia Gonzalez caracterizou o racismo como a sintomática que caracteriza a neurose cultural brasileira ${ }^{10}$. Dessa forma, ele está presente no

\footnotetext{
8 SOUZA, Jessé. A ralé brasileira: quem é e como vive. Belo Horizonte: Editora da UFMG, 2009.

9 HALL, Stuart. A identidade cultural na pós-modernidade: tradução Tomaz Tadeu da Silva, Guacira Lopes Louro - 10.ed. - Rio de Janeiro: DP\&A, 2005, p.63.

10 GONZALEZ, Lélia. "Racismo e sexismo na cultura brasileira". In: SILVA, L. A. et al. Movimentos sociais urbanos, minorias e outros estudos. Ciências Sociais Hoje, Brasília, ANPOCS n. 2, p. 223-244, 1983.
} 
cotidiano e em atravessamentos com o sexismo. Visto que a turma parece reconhecer o racismo que existe no Brasil e que muitas vezes reproduz essa lógica, no último questionamento, inspirado nas palestras e escritos de Angela Davis, quis saber quais seriam as atitudes antirracistas que cada estudante poderia aderir no seu cotidiano para mudar a realidade. Com essa pergunta, busquei implicar as ações, pensamentos da turma na problemática em questão. A resposta mais comum estava no ato de repensar suas falas e piadas em relação a pessoas não brancas. A metodologia possibilitou, além de compreender o conceito de raça, reconhecer que o racismo configura-se como um sistema de opressão perpetuado pelas práticas do dia a dia.

Figura 2 - Fragmentos: classe e raça

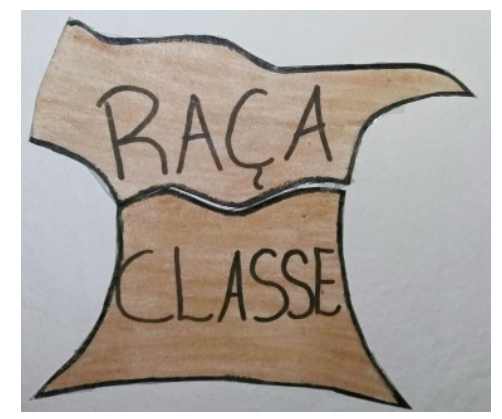

Fonte: elaborada pela autora.

Também foram mencionados dados relacionados ao genocídio da população negra. O Atlas da Violência de 2017, aponta que a cada 100 pessoas assassinadas, em 2017, 71 eram negras ${ }^{1}$.

\section{Relações de Gênero}

A discussão sobre gênero teve início com uma breve retomada histórica acerca das contribuições feministas para o debate público sobre a inferioridade imposta pela sociedade patriarcal. Com isso, a luta das mulheres negras contra o discurso hegemônico do feminismo branco também representou um tema apresentado e debatido, tomando como exemplos os ataques diretos e os silenciamentos que Marielle sofria na Câmara de Vereadores. Ao final da aula, o vídeo denominado "Último pronunciamento de Marielle Franco antes de ser

\footnotetext{
11 LIMA, Wesley. Brasil: um país marcado pelo genocídio da sua população negra, pobre e periférica. MST. Disponível em: https://mst.org.br/2018/05/18/brasil-um-pais-marcado-pelogenocidio-da-sua-populacao-negra-pobre-e-periferica/ Acessado em: 21/02/2021 .
} 
executada no Rio de Janeiro" 2 foi exibido para a turma conhecer, brevemente, a sua fala e posicionamentos. Seu último pronunciamento aconteceu no dia 8 de março, Dia Internacional da Mulher. Ao longo de todo o vídeo, seu discurso é interrompido por gritos e conversas paralelas, até mesmo atrapalhado pela entrega de uma rosa por um dos vereadores. Depois dessa exibição, conversamos sobre os estereótipos que cercam ser mulher. Principalmente, como outros marcadores sociais modificam essa experiência, e como ela não é única. Nem todas são designadas como mulheres no nascimento, mas isso não faz com que elas não o sejam.

\section{Figura 3 - Fragmentos: classe, raça e gênero}

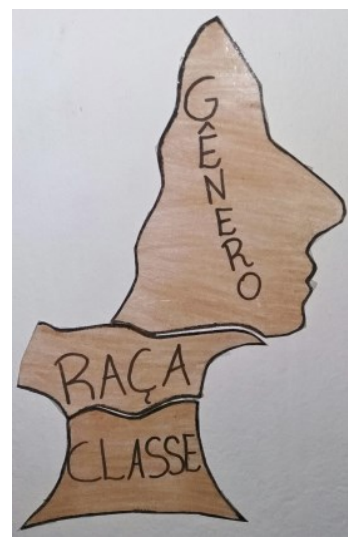

Fonte: elaborada pela autora.

Ao falar das abordagens científicas sobre o termo, o conceito de Guacira Lopes Louro ${ }^{13}$ que compreende gênero como um processo de inscrição nos corpos, no contexto de uma determinada cultura e com as marcas desta ilustrou o debate. Perguntas questionando o gênero que as roupas têm, entre outras indagações fizeram parte da conversa sobre esse segmento. Desse modo, retomamos como essas práticas sociais não são naturais. E como Durkheim indica a importância da educação nesse processo, para além das consciências individuais.

\section{Sexualidade}

O espectro da sexualidade compreende a expressão da atração sexual

\footnotetext{
12 MÍDIA LIVRE. Último pronunciamento de Marielle Franco antes de ser executada no Rio de Janeiro. Youtube, 15 de mar. 2018. Disponível em: https://www.youtube.com/watch? $v=D a 7 d q C q E J m A$ Acessado em: 21/02/2021.

13 LOURO, G.L. Pedagogias da sexualidade. LOURO, G.L.(org.). In: O corpo educado: pedagogias da sexualidade. Belo Horizonte: Autêntica, 2010.
} 
e/ou romântica. Marielle Franco se posicionava como uma mulher bissexual, tendo relatado que isso causou conflitos na sua relação familiar ao assumir um relacionamento com uma mulher. Nessa parte, foram apresentados os dados do Grupo Gay da Bahia de 2017 sobre o assassinato de pessoas LGBTQI's. O relatório aponta que, a cada 19 horas, uma pessoa LGBTQI+ morre de forma violenta, vítima da LGBTQIfobia ${ }^{14}$. A partir desse dado alarmante, retomei o conceito de fato social e o elemento da coerção.

Figura 4 - Fragmentos: classe, raça, gênero e sexualidade

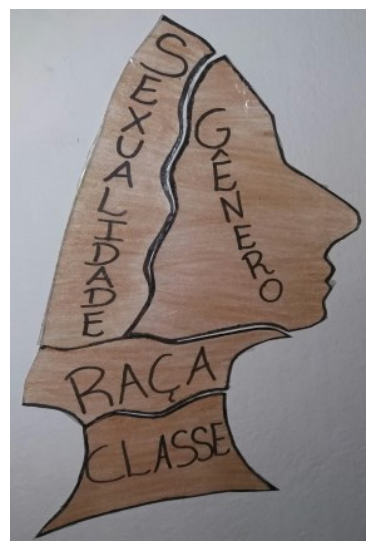

Fonte: elaborada pela autora.

Revisamos juntos como as categorias anteriores poderiam representar um fato social, como poderíamos classificar as características gerais, exteriores e de coerção. Ao falar sobre coerção, sexualidade e identidade de gênero, destaquei as violências simbólicas e físicas que as pessoas LGBTQI's sofrem. Conversamos sobre quais seriam as origens desses preconceitos, com isso, as concepções de moralidade e coerção de Durkheim foram retomadas. "Em se tratando de máximas puramente morais, a consciência pública reprime todo ato que as ofenda através da vigilância que exerce sobre a conduta dos cidadãos e das penas especiais de que dispõe"15. Dessa maneira, a perseguição, a censura em relação à expressão sexual e de gênero desses grupos é interpretada como um questão social e política.

\section{Protagonismo}

Ao trazer o conceito de protagonismo, tratamos de uma retomada da

\footnotetext{
14 AUN, Heloisa. Brasil é 2007, p.3.o país que mais mata LGBTs no mundo: 1 a cada 19 horas. Catraca livre, 2018. Disponível em: https://catracalivre.com.br/cidadania/brasil-mais-mata-lgbts-1-cada-19horas/. Acessado em: 21/02/2021.

15 DURKHEIM, Émile. As regras do método sociológico. -3ª.ed.- São Paulo: Martins Fontes,
} 
história de vida de Marielle. Por meio de muitas superações, suas experiências de vida e ressignificação em projetos e ações para o bem de sua comunidade.

Figura 5 - Fragmentos: classe, raça, gênero, sexualidade e protagonismo

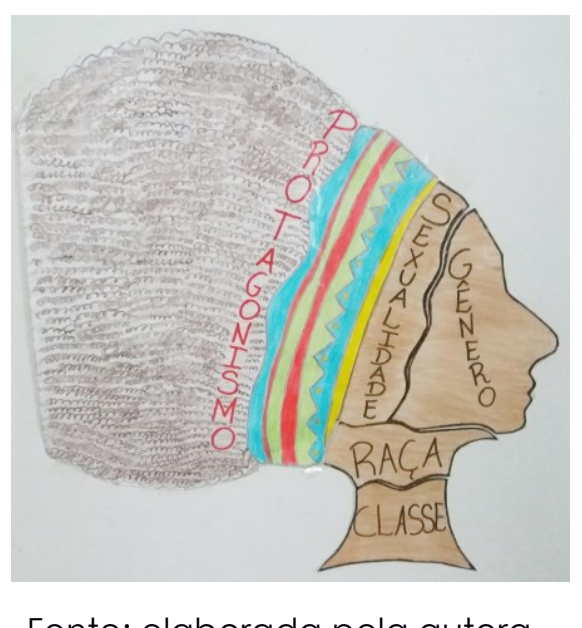

Fonte: elaborada pela autora.

Quando a silhueta se formou completa no quadro, a turma toda pareceu surpresa. Perguntaram sobre a origem do desenho e da ideia. Contei que pensei em uma forma diferente de apresentar a vida da Marielle e contei com a ajuda de uma colega para produzir o desenho. Pelas expressões e comentários, no final da aula e do estágio, a maioria pareceu gostar da proposta.

Importante frisar, que ao longo da aula, os conceitos anteriores eram retomados e aprofundados na procura de mostrar como eles se relacionam interseccionalmente. A interseccionalidade é uma abordagem teóricametodológica de interpretar a realidade social. Esse conceito propõe a leitura das identidades de gênero, racial e posição social não como concorrentes, mas como parte de uma sociedade capitalista que divide e vulnerabiliza determinadas pessoas com base em suas identidades ${ }^{16}$. Cada fragmento foi separado para que, ao final fosse possível compreender as identidades não isoladamente, na verdade, elas fazem parte de um todo, o sujeito. Ao contar a história de Marielle, ao longo dessa colagem, o encontro de influências entre os elementos individuais e coletivos na história de vida de uma pessoa ficaram evidentes. Perspectiva muito trabalhada por Émile Durkheim.

16 AKOTIRENE, Carla. O que é interseccionalidade? Belo Horizonte: Letramento - Justificando, 2018, p.14. 


\section{Sobre os sentimentos docentes}

A proposta de trabalhar a história de Marielle causou uma movimentação de diversos sentimentos. A escola deve ser o lugar em que educadores e educadoras não demonstram emoções? A discussão sobre corpo e docência é identificada em diversos textos por bell hooks, intelectual negra estadunidense. A autora apresenta a negligência da percepção corporal por profissionais de educação desde sua formação ${ }^{17}$. A partir de sua leitura, surgem também questionamentos sobre o espaço das emoções nesse local e como a identidade docente, muitas vezes através da promessa de objetividade, acaba por silenciar uma certa humanização da docência. Será que esse espaço pode existir? Essa pergunta continua sem uma resposta exata. Refletir sobre o corpo e as emoções presentes no trabalho docente também perpassa as discussões contemporâneas das ciências sociais acerca do lugar de fala. Com isso, é importante salientar o peso de ocupar esse lugar, principalmente como professora.

Mesmo com todos esses questionamentos pessoais, a aula expositiva gerou uma conversa muito produtiva, pois cada estudante participou com questões e exemplos de seu cotidiano. No final da aula, uma aluna pediu para salvar o vídeo do último pronunciamento de Marielle em seu celular. A partir das inquietações da turma e minhas, os objetivos de compartilhar o papel crítico da Sociologia e ocupar esse espaço como resistência foram atingidos.

\section{Considerações finais}

O planejamento dessa aula mudou minhas perspectivas sobre as implicações de ser professora. Fui capaz de perceber o valor em produzir materiais problematizadores, ao receber o reconhecimento da turma. Por conseguinte, as emoções e o bem-estar de quem exerce a docência tornaram-se preocupações minhas. Em planos futuros, articular atividades com outras formas de interação também representa um aprendizado dessa prática pedagógica. Em suma, analisar as desigualdades, a partir de um viés científico com a Sociologia, estabelece um potencial transformador. As reivindicações de Marielle Franco continuarão ecoando nos exercícios e planejamentos de aulas futuras.

\footnotetext{
17 hooks, bell. Eros, erotismo e o processo pedagógico. In: LOURO, Guacira Lopes (org). O Corpo Educado: Pedagogias da sexualidade. Belo Horizonte: Autêntica, 2010.
} 


\section{Referências}

AKOTIRENE, Carla. O que é interseccionalidade? Belo Horizonte: Letramento Justificando, 2018.

AUN, Heloisa. Brasil é o país que mais mata LGBTs no mundo: 1 a cada 19 horas. Catraca livre, 2018. Disponível em: https://catracalivre.com.br/cidadania/brasilmais-mata-lgbts-1-cada-19-horas/. Acessado em: 21/02/2021.

BOURDIEU, Pierre. A ilusão biográfica. In: Razões práticas: sobre a teoria da ação. 5. ed. São Paulo: Papirus Editora, 2005, p.74-82.

DURKHEIM, Émile. As regras do método sociológico. $-3^{a}$.ed.- São Paulo: Martins Fontes, 2007.

ESCOBAR, Geanine. Marielle, presente! Hoje e sempre. Dezanove, 2018. Disponível em: https://dezanove.pt/marielle-presente-hoje-e-sempre-1168931 Acessado em: $21 / 02 / 2021$.

GONZALEZ, Lélia. "Racismo e sexismo na cultura brasileira". In: SILVA, L. A. et al. Movimentos sociais urbanos, minorias e outros estudos. Ciências Sociais Hoje, Brasília, ANPOCS n. 2, p. 223-244, 1983.

HALL, Stuart. A identidade cultural na pós-modernidade: tradução Tomaz Tadeu da Silva, Guacira Lopes Louro - 10.ed. - Rio de Janeiro: DP\&A, 2005.

hooks, bell. Eros, erotismo e o processo pedagógico. In: LOURO, Guacira Lopes (org). O Corpo Educado: Pedagogias da sexualidade. Belo Horizonte: Autêntica, 2010.

LAHIRE, B. "Viver e interpretar o mundo social: para que serve o ensino de Sociologia?" In: GONÇALVES, D. N. (Org.). Sociologia e juventude no ensino médio: formação, PIBID e outras experiências. Campinas: Pontes Editores. (pp. 15-30), 2014.

LIMA, Wesley. Brasil: um país marcado pelo genocídio da sua população negra, pobre e periférica. MST. Disponível em: http://www.mst.org.br/2018/05/18/brasilum-pais-marcado-pelo-genocidio-da-sua-populacao-negra-pobre-eperiferica.html Acessado em: 21/02/2021.

LOURO, G.L. Pedagogias da sexualidade. LOURO, G. L.(org.). In: O corpo educado: pedagogias da sexualidade. Belo Horizonte: Autêntica, 2010.

MAIA, Dhiego. Bolsonaro propõe reduzir verba para cursos de sociologia e filosofia no país. Folha de S.Paulo. Disponível em https://wwwl.folha.uol.com.br/educacao/2019/04/bolsonaro-propoe-reduzirverba-para-cursos-de-sociologia-e-filosofia-no-pais.shtml Acessado em: $21 / 02 / 2021$.

MÍDIA LIVRE. Último pronunciamento de Marielle Franco antes de ser executada no 
Rio de Janeiro. Youtube, 15 de mar. 2018. Disponível em: https://www.youtube.com/watch?v=Da7dqCaEJmA Acessado em: 21/02/2021.

SOUZA, Jessé. A ralé brasileira: quem é e como vive. Belo Horizonte: Editora da UFMG, 2009.

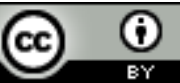

This work is licensed under a Licence Creative Commons Attribution 4.0 International License. 